\title{
Design and Development of High Efficiency Solar Energy based Water Purification System using Density Driven Method
}

\author{
${ }^{1}$ Shivaraj B. Hiremath \\ Student, Department of EEE, Tontadarya College of \\ Engineering, Gadag, Karnataka, India \\ ${ }^{3}$ Praveen R. Tonne \\ Student, Department of EEE, Tontadarya College of \\ Engineering, Gadag, Karnataka, India
}

\author{
${ }^{2}$ Preeti R. Shettar \\ Student, Department of EEE, Tontadarya College of \\ Engineering, Gadag, Karnataka, India \\ ${ }^{4}$ Aishwarya S. Sajjan \\ Student, Department of EEE, Tontadarya College of \\ Engineering, Gadag, Karnataka, India
}

\author{
${ }^{5}$ Jagadeeshwar G. Shivanagutti \\ Assistant Professor, Department of EEE, \\ Tontadarya College of Engineering, Gadag, \\ Karnataka, India
}

\begin{abstract}
In this paper, we are making a Water Purifier which works on Solar Energy. The basic principle behind this is Solar Pasteurization. The Solar Water Pasteurization System works on Density Difference Flow principle has been designed, built and tested. The system contains no valves and regulates flow based on the Density Difference between different layers of Purification System. This Paper includes a Water Quality Monitoring System through various sensors which are used to test the water samples and measured values are displayed. The system consists of three Water Quality Monitoring Sensors to monitor the standards of water and it relies on Arduino Uno and GSM to send the information to the watching center. This Paper delivers a power efficient and effective solution in the domain of water quality monitoring system. It's a true time system which is able to endlessly measure the standards of water and can send the measured values to the watching center when on each predefined time. Experiments with the prototype systems presented in this paper show that Density Driven Systems are an attractive option to existing Solar Water Pasteurization approaches.
\end{abstract}

Keywords: Pasteurization; Purification; Monitoring; Density Driven;

\section{INTRODUCTION}

Waterborne pathogens in developing countries cause several billion cases of disease and up to 10 million deaths each year, at least half of which are children. In the rural areas of developing countries, boiling is the means most often used for purifying water for food preparation and drinking. However, boiling is relatively expensive, consumes substantial amounts of fossil energy and the associated wood gathering contributes to depletion of forests. Among available alternatives, solar water pasteurization is one of the most promising approaches for energy efficient, cost effective [2], robust and reliable solution to these problems. There is a great and urgent need to supply environmentally sound technology for the provision of drinking water for rural areas. Water is one of the essential natural resources that have been gifted to mankind. But the rapid development of the society and numerous human activities speeded up the contamination and deteriorated the water resources. Water is the most common liquid on the earth .Pure drinking water is necessary for human survival. The water supply for drinking water is either ground water or surface water. The water from each source contains sediments and other solids. The decreasing availability of water has necessitated in the search for fresh sources of drinking water. The available water in many areas in the country is brackish, saline or impure. In our country pure drinking water is a major problem in tribal/rural area. There are many processes available for purification of drinking water like Chlorine tablets, Pot chlorination of wells, Slow and rapid sand filters, Fluoride removal, Reverse osmosis plants, etc .In this project, we are making a water purifier which works on solar energy [2]. The basic principle behind this project is Solar Pasteurization [1]. We are using solar energy which is a renewable source, abundant and cheap. Here, we use GSM based Arduino Uno which monitors the pure or treated water. This purifier can be used in remote and rural areas where there is no electricity [3], [5].

\section{OBJECTIVE}

- $\quad$ To provide water purification system working on renewable energy and reduce the use of fossil energy

- To provide pure drinking water at low cost to the rural areas

- To make the system energy efficient

- To make the system portable and user friendly

- To use of moderate heat or radiation to kill disease causing microbes

- To purify the water for drinking and household purposes through the usage of solar energy

- To use of Low-Technology solution that works to capture the heat and energy from the sun to make water cleaner and healthier for human use and consumption

- To destroy Waterborne pathogens which are present in the drinking water 
- To make a device/equipment which provide water for drinking purpose and design a village level water purification system that runs on solar power

\section{SYSTEM IMPLEMENTATION}

\section{A. Block Diagram}

As shown in the below figure the impure water is taken at top of the container then it is given to the density driven system. In the system it contains 4 to 5 layers such as Activated Carbon, Aluminum Sulphate, Cotton, Fine Sand, Gravels. Then the water is flows through the Parabolic Collector in that some of the microorganisms are killed with the help of solar radiations. The water is again flows through the Heat Exchanger to convert hot water to normal cold. At the bottom container the Pure Water is obtained. The pure water is monitored hear because to check whether the water is suitable for drinking or not by using some of the sensors like $\mathrm{pH}$, Turbidity and Temperature. Various sensors output is in Analog Signals then it convert to Digital Signals by using ADC. ADC is given to the Arduino Uno in that program is built then various parameters values are displayed on LCD and also give the message to the mobile by GSM.

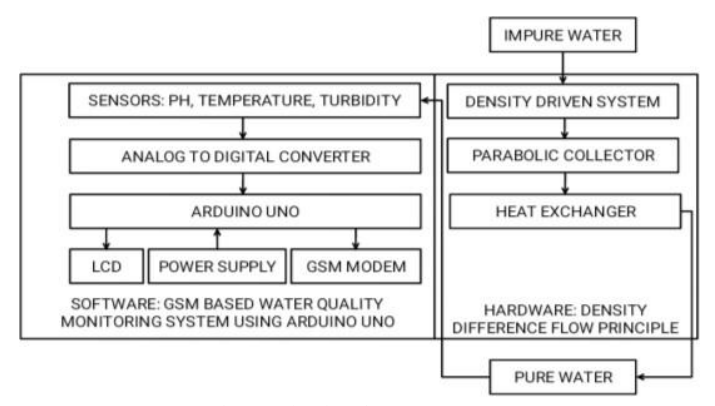

Fig.1 Block Diagram

\section{B. Hardware System Description: Using Density Driven System}

As shown in the below figure the impure water is taken at top of the container then it is given to the density driven system. In the system it contains 4 to 5 layers such as Activated Carbon, Aluminum Sulphate, Cotton, Fine Sand, Gravels. Then the water is flows through the Parabolic Collector in that some of the microorganisms are killed with the help of solar radiations. The water is again flows through the Heat Exchanger to convert hot water to normal cold. At the bottom container the Pure Water is obtained.

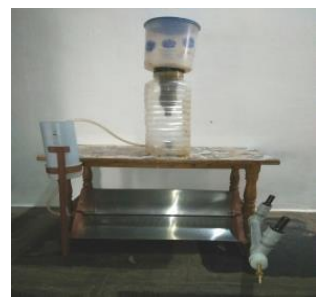

Fig.2 Density Driven System
Layers used in the Density Driven System are as follows,

Fig. 3(a) Shows the Activated Carbon Layer - It is effective in removing the Colour, taste and odour from the treated water. It is used to adsorb organic, chemical and mineral impurities present in the muddy water. Fig. 3(b) Shows Aluminum Sulfate Layer - It causes suspended impurities to coagulate into larger particles and then it is filter out. It is widely used as a flocculent to clarify the turbidity in water. Fig. 3(c) Shows Cotton Layer - By passing the water through an effective filter, most cholera bacteria and other pathogens are removed. It traps any physical debris present in the water. Fig. 3(d) Shows Fine Sand Layer - It is used to removal of suspended matter, as well as floating and sinkable particles. It purifies the insoluble particles present in the muddy water. Fig. 3(e) Shows Gravels Layer - It is used to clean the water from impurities. It can trap large particles and help to oxygenate the water. It slows down the flow of water which helps in enhancing the absorption property.

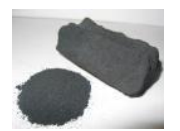

Fig. (a)

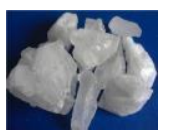

Fig. (b)

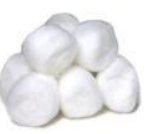

Fig. (c)

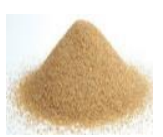

Fig. (d)

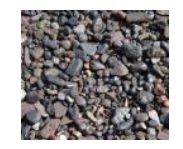

Fig. (e)
Fig. 3 Layers Used In Density Driven System

Different Components used in Hardware System are as follows,

As shows in the below figure the Parabolic Solar Collector is made up of stainless steel used for obtaining maximum reflection of incident sunlight. It will help to kill the microorganisms present in the water with the help of solar radiations. It is set in the North-South direction and tilted at an angle of 45 with respect to sun.

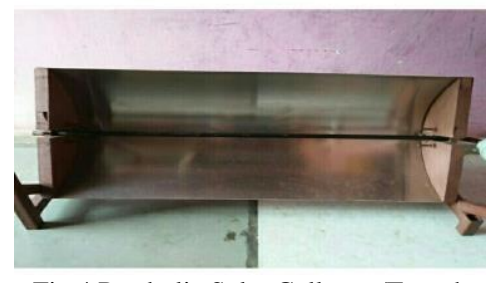

Fig.4 Parabolic Solar Collector/Trough

Copper Pipe is shown in the below figure, it is placed at the focal point of the parabolic collector. It is $45 \mathrm{~mm}$ from the base of the parabolic through.

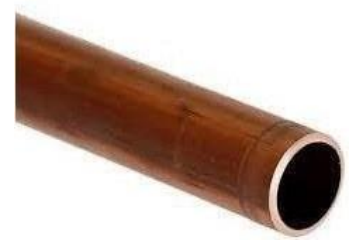

Fig.5 Copper Pipe/Tube 
Heat Exchanger is shown in below figure, it is made from 2 inch diameter PVC tubing and length is around 22 inches. It converts hot water to normal cold water.

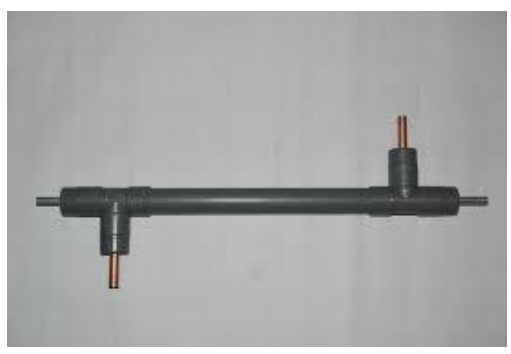

Fig.6 PVC Heat Exchanger

\section{Software System Description :GSM Based Water Quality Monitoring System Using Arduino Uno}

$\mathrm{pH}$ is the negative $\log$ of the activity of the hydrogen ion in the solution. A $\mathrm{pH}$ sensor helps to measure the acidity or alkalinity of the water with the value between $0-14$. The Standard $\mathrm{pH}$ values of the pure water is 6.5. The $\mathrm{pH}$ sensor shown in the below figure is used to measure the $\mathrm{pH}$ value of the water.

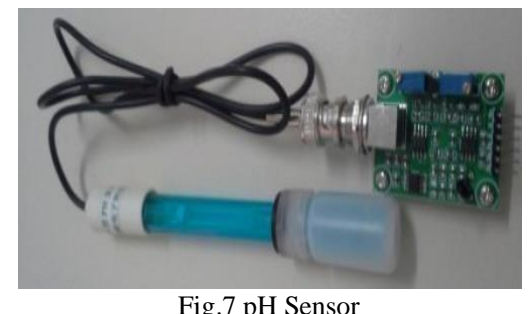

Temperature sensor is shown in the below figure, Why we check temperature because we can see the characteristics of the water such as Chemical, Biological and Physical as well as Health effect. The Standard value is 20-30 degree Celsius. It is used to measure the temperature of the water

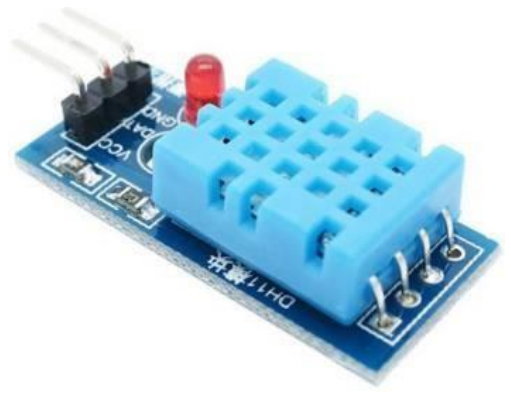

Fig.8 Temperature Sensor

The Turbidity sensor is shown in the figure. It is one of the important and critical parameter of the drinking water. It gives the water processing efficiency. The Standard value is 1 NTU-5NTU. It is used to measure the turbidity of the water.

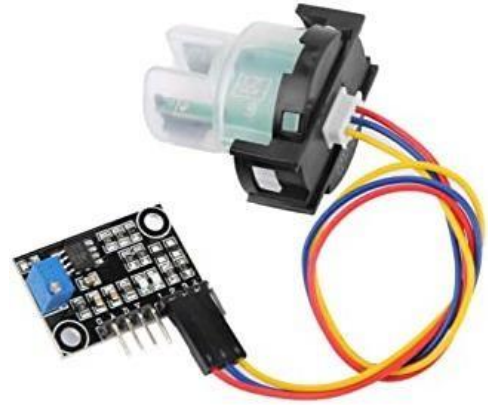

Fig.9 Turbidity Sensor

Arduino Uno is shown in the below figure, it is a microcontroller board based on the ATmega328. The program is built in the Arduino. It is used to perform the monitoring operation of water parameters.

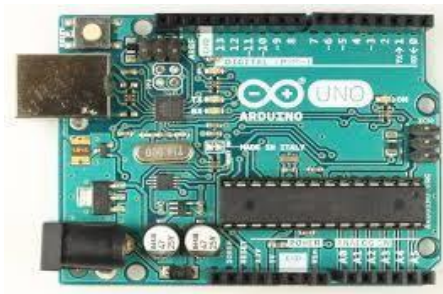

Fig.10 Arduino Uno R3

\section{WORKING PROTOTYPE MODEL}

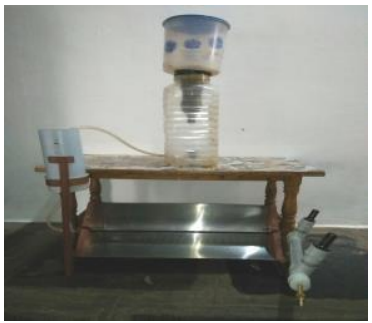

Fig.11 Hardware System

The impure water is collected in the top container (at a height of $254 \mathrm{~cm}$ ) and it is made passed through the density driven system which consists of 5 layers arranged alternatively. The layers are namely: Activated Carbon, Aluminum Sulfate, Cotton, Fine Sand and Gravel. Through these layers density difference of the impure water occurs and due to this the impure water gets purified and is collected at the bottom container. The purified water is made passed through the copper pipe which is coated with black color to absorb solar radiation is placed at the focal point of the parabolic collector. The parabolic collector collects the solar radiation and focus at a focal point where the copper pipe is placed, due to this water inside the copper pipe gets heated and the temperature of the water gets increased, because of this the microbes if so present gets killed. Finally we get the pure water. 


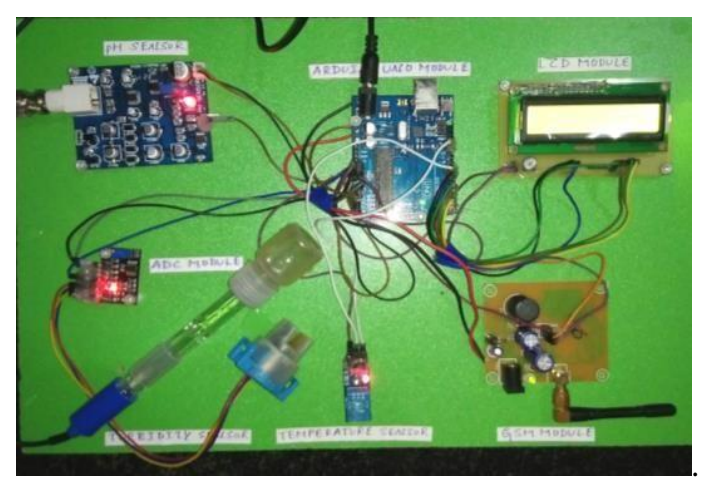

Fig. 12 Software Systems

The pure water can be monitored by using A GSM Based Water Quality Monitoring System using Arduino Uno. We are using 3 sensors namely: $\mathrm{pH}$, temperature and turbidity sensors. All the sensors are immersed in the container containing the purified water which is subjected to its quality test and these sensors are connected to the ADC, ADC is connected to the Arduino Uno, in this coding is dumped, output of the Arduino Uno is given to the 2 systems namely: GSM and LCD [3], [5].

\section{RESULTS AND ANALYSIS}

Case-1 Location: Gadag; Type: Ground Water

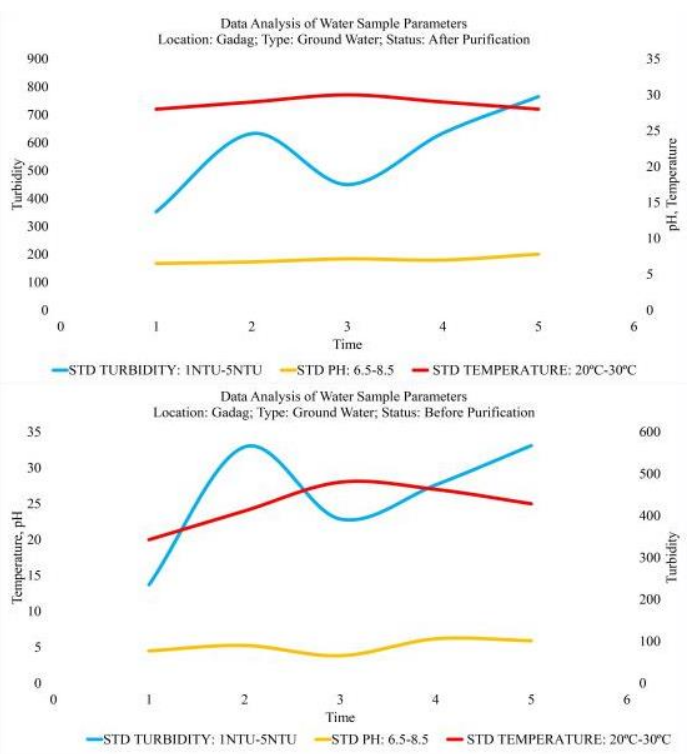

Fig13. Variation of Water Parameters of Gadag
Case-2 Location: Savadatti; Type: River Water
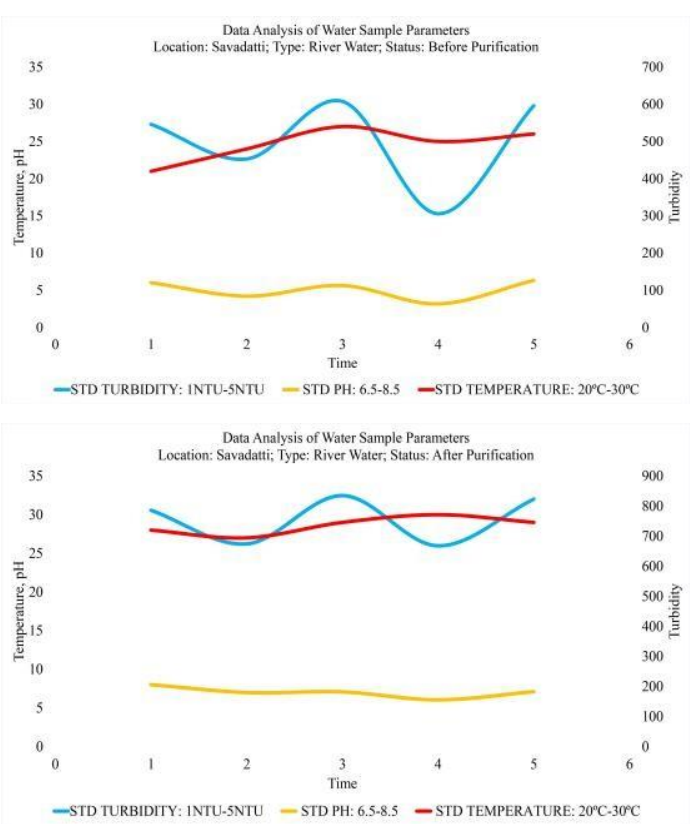

Fig.14 Variation of Water Parameter of Savadatti Case-3

Location: Badami; Type: Bore Well Water

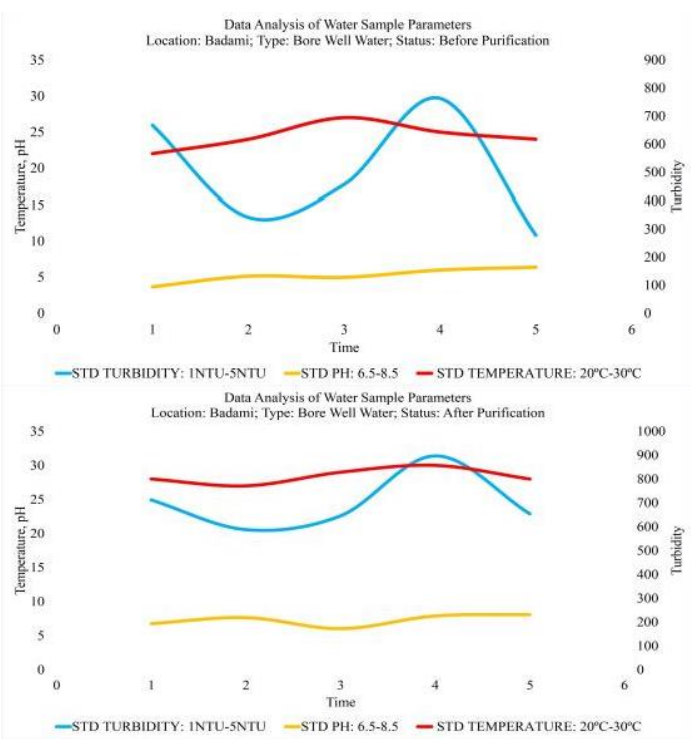

Fig.15 Variation of Water Parameter of Badami 
Case-4 Location: Raibag; Type: Rain Water

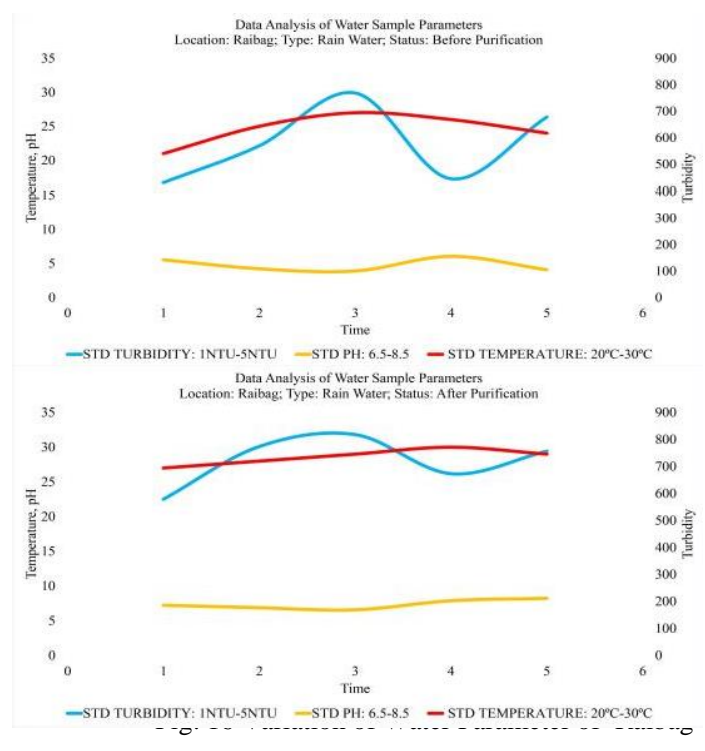

Case-5 Location: Muddebihal; Type: Open Well Water
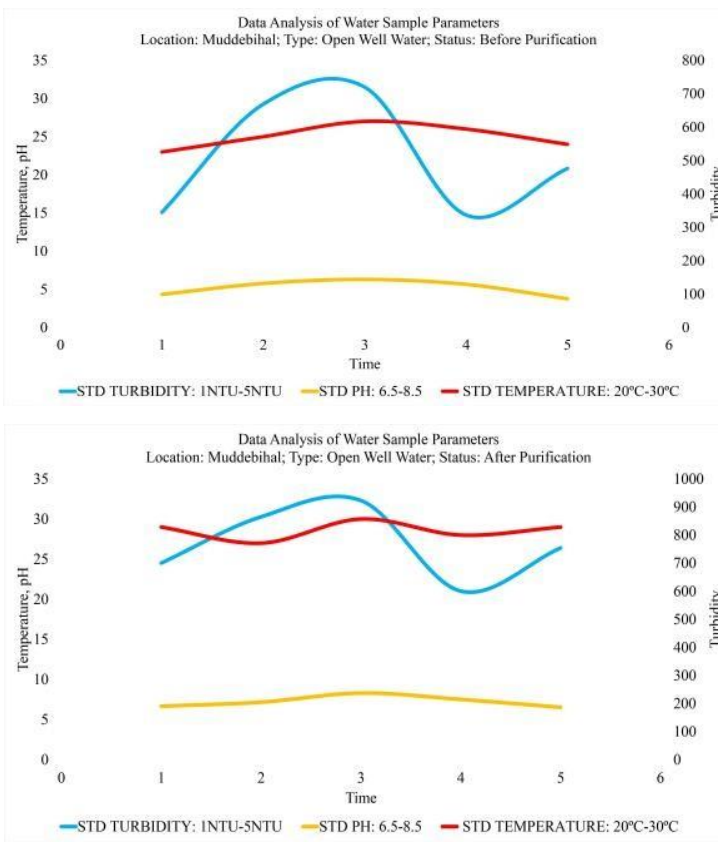

Fig. 17 Variation of Water Parameter of Muddebihal

We have performed the water purification and tested the different water samples from different locations for different time intervals. Before purification, the water parameters are not meeting the standard values of $\mathrm{pH}$, temperature and turbidity. After purification, the water parameters are nearly equal to the standard values of $\mathrm{pH}$ around $6.5-8.5$, temperature stays between $20^{\circ} \mathrm{C}-30^{\circ} \mathrm{C}$. The turbidity of water will be around $0.5 \mathrm{NTU}-1 \mathrm{NTU}$ which can be measured from the experimental results and it is fit for drinking purpose.

\section{ADVANTAGES, DISADVANTAGES AND APPLICATIONS}

\section{A. Advantages:}

- It is a viable water treatment method which helps in improving the microbiological quality of drinking water

- It can be easily applied at small communities of the area that do not have a centralized water treatment plant

- At household level, it can be undertaken under the responsibility of the individual user

- It is economical and has a low investment cost as it relies on locally available renewable energy resources

- It is an energy-efficient, cost-effective, robust and reliable system

- It produces water of high quality

- Maintenance is almost negligible

- Any type of water can be purified into potable water by means of this process

- The system will not involve any moving parts and will not require electricity to operate

- Wastage of water will be minimum

\section{B. Disadvantages:}

It is dependent on suitable climate and weather conditions, especially on places where convenient solar radiation exists. For instance, during days of continuous rainfall or cloudy days, it does not perform satisfactorily

\section{Applications:}

- In Rural areas

- Educational Institutes

- Hospitals

- Domestic purposes

- Residential areas., etc

\section{CONCLUSION}

This paper presents a solar energy based water purification system using density driven method. The system presented is the density driven system to include oxidized copper pipe and a heat exchanger. The density driven system has an advantage that it does not have a valve to maintain. With no moving parts to fail the system becomes more very reliable. The use of copper pipe allows for easy maintenance. The copper pipe can be removed from the system for cleaning. Also, any damaged copper pipe can easily be removed and replaced. Experiments conducted with the prototype systems presented in this paper shows that density driven system incorporating copper pipe are an attractive option to existing solar water pasteurization approaches. The real-time water quality monitoring system for real-time applications which is 
efficient and low cost has been tested after the implementation. This can help in preventing diseases caused due to impure water and the presence of metals. It has a positive meaning to strengthen environmental protection and to improve environmental performance throughout the community. The 3 water parameters are monitored in this system which are namely: $\mathrm{pH}$, temperature and turbidity. The results of the test for all times have been successful. We conclude that all the objectives of the proposed system have been achieved. Only by replacing the corresponding sensors and changing the relevant software programs, this system can be used to monitor other water quality parameters.

\section{ACKNOWLEDGEMENT}

The satisfaction of the successful completion of any task would be incomplete without the expression of gratitude to the people who have made it possible. We acknowledge all the people who have guided and encouraged us. We would like to take this opportunity to thank our guide Prof. Jagadeeshwar G. Shivanagutti, Assistant Professor, Department of Electrical and Electronics Engineering, for his immense guidance and support, without which the research work would have been unthinkable. We express our deep sense of gratitude to Dr. Iranna. M. Korachagaon, Vice Principal and Head of Department of Electrical and Electronics Engineering, for his immense support. We extend our gratitude to Dr. M. M. Awati, Principal, Tontadarya College of Engineering Gadag, for his generous support in all regards.

\section{REFERENCES}

[1] Duff, W.S., Hodgson, D., 2001. A passive solar water pasteurization system without valves. In: Proceedings of the 2001 Annual Conference of the American Solar Energy Society, April, Washington, DC, American Solar Energy Society, Boulder, Colorado.

[2] Duff, W.S., Hodgson, D., 2002. A simple high efficiency solar water purification system. In: Proceedings of the 2002 Annual Conference of the American Solar Energy Society, 15-20, Reno, Nevada, American Solar Energy Society, Boulder, Colorado.

[3] Alkandari, M. Alnasheet, Y. Alabduljader, \& Moein S. M, "Wireless sensor network (WSN) for water monitoring system", Report: a Case study of Kuwait beaches. International Journal of Digital Information and Wireless Communications vol.1, no.4, 2011. pp.709-717.

[4] Bhardwaj, R M. "Overview of Ganga River Pollution", Report: Central Pollution Control Board, Delhi, 2011.

[5] Dong He, Li-Xin Zhang, "The Water Quality Monitoring System based on Wireless Sensor Network" Report: Mechanical and Electronic Information Institute, China University of Geo Science, Wu Hen, China, 2012.

[6] Liang Hu, Feng Wang, Jin Zhou \& Kuo Zhao "A Survey from the Perspective of Evolutionary Process in the Internet of Things", International Journal of Distributed Sensor Networks, 2015, Article ID 462752,

[7] Quio Tie-Zhu, Song Le, "The Design of Multiparameter On line Monitoring System of Water Quality based on GPRS",
[8] Report: Advanced Transducers and Intelligent Control System Lab, Taiyuan Technical University, Taiyuan, China, 2010.

[9] Rasin, Z \& Abdullah M. R, "Water Quality Monitoring System Using Zigbee Based Wireless Sensor Network", International Journal of Engineering \& Technology IJET.

[10] Tuan Le Dinh, Wen Hu, Pavan Sikka, Peter Corke, L. Overs, Stephen Brosman, "Design and Deployment of a Remote Robust Sensor Network: Experiences from Outdoor Water", 32nd IEEE Conf. on Local Computers, Feb., 2007, pp.799-806

\section{AUTHOR DETAILS}

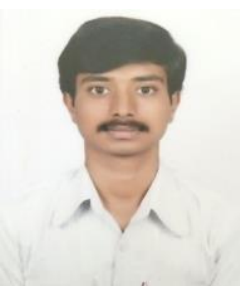

${ }^{1}$ Shivaraj. B. Hiremath was born in Savadatti Town, Belgaum District, Karnataka State, India, on $27^{\text {th }}$ November 1998. He is now pursuing in B.E ( $4^{\text {th }}$ year) in Electrical and Electronics Engineering, Tontadarya College of Engineering, Gadag, Karnataka affiliated to Visvesvaraya Technological University, Belagavi, Karnataka. He is interested in Electrical Machines and Power Electronics.

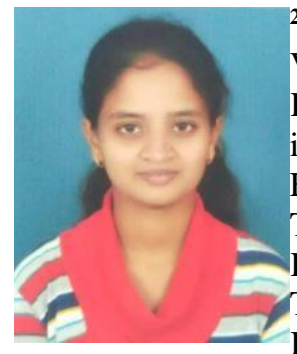

${ }^{2}$ Preeti. R. Shettar was born in Kerur Village, Badami Town, Bagalkot District, Karnataka State, India, on $6^{\text {th }}$ July 1998 . She is now pursuing in B.E ( $4^{\text {th }}$ year) in Electrical and Electronics Engineering, Tontadarya College of Engineering, Gadag, Karnataka affiliated to Visvesvaraya Technological University, Belagavi, Karnataka. She is interested in Electrical Power Generation and Power Electronics.

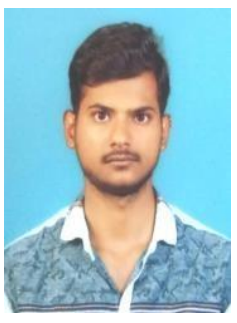

${ }^{3}$ Praveen. R. Tonne was born in Bhiradi Village, Raibag Town, Belgaum District, Karnataka State, India, on $22^{\text {nd }}$ October, 1998. He is now pursuing in B.E ( $4^{\text {th }}$ year) in Electrical and Electronics Engineering, Tontadarya College of Engineering, Gadag, Karnataka affiliated to Visvesvaraya Technological University, Belagavi, Karnataka. He is interested in Power System and Power Electronics.

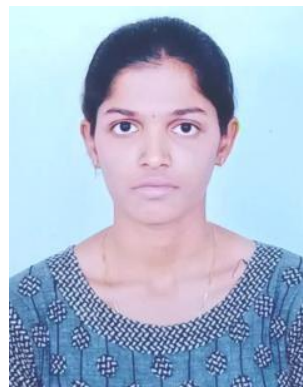

${ }^{4}$ Aishwarya. S. Sajjan was born in Tangadagi Village, Muddebihal Town, Vijayapur District, Karnataka State, India, on $15^{\text {th }}$ September, 1998. She is now pursuing in B.E $\left(4^{\text {th }}\right.$ year $)$ in Electrical and Electronics Engineering, Tontadarya College of Engineering, Gadag, Karnataka affiliated to Visvesvaraya Technological University, Belagavi, Karnataka. She is interested in Electrical Power Generation and Power Electronics. 


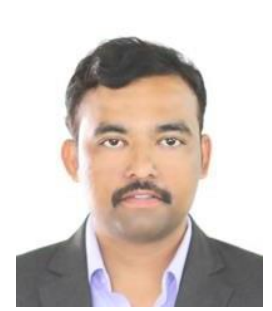

${ }^{5}$ Jagadeeshwar. G. Shivanagutti was born on 26th June, 1986 in Kushtagi, Koppal District, Karnataka State, India. $\mathrm{He}$ completed his Engineering Graduation from PDACE, Gulbarga, in Electrical Stream. Then he completed his M.Tech in Energy Systems and Management from SJCE, Mysore. Currently He is working as Assistant Professor in Tontadarya College of Engineering(NBA accredited), Gadag, Karnataka. He has been guiding several UG Projects. His areas of interests include Energy Conservation, Solar Energy Harnessing, Estimation and Utilization, Energy Management, Energy Audit and Renewable Energy Sources, Electrical Vehicles. He has published many international and national papers. His membership includes International Association of Engineers (IAENG), Institute, IAENG Society of Industrial Engineering \& IAENG Society of Electrical Engineering, Life time Professional Member of the Institute of Scholars. Life time professional member of Institute For Engineering Research and Publication (IFERP). He is a nominated faculty under NISP Implementation Program in HEI by MHRD Innovation Cell, Government of India. He received "InSc Best Teacher Award 2019" from Institute of Scholars(InSc). 